\section{NEW GUIDANCE ON INCORPORATION}

NASDAL, the National Association for Specialist Dental Accountants and Lawyers, has issued new guidance to help dentists understand the complexities of incorporation. If you are considering incorporation or want to check that the advice you have been given is accurate, consult the guidance on the NASDAL website: http://www.nasdal.org. uk/docs/NASDAL-GuidanceIncorporation.pdf.

NASDAL has recently helped dentists who had incorporated without considering the full implications of the process. NASDAL aims to set the record straight for others in the profession. The new guidance covers:

- The assets and liabilities to be included in the limited company

- Goodwill

- NHS contract issues

- The NHS pension scheme.

NASDAL's message to dentists is that if incorporation seems straightforward, then more research is essential. Incorporation can be advantageous but it must be carefully weighed up with the help of specialist advisors.

\section{PRESERVE YOUR PATIENTS' PRECIOUS CELLS}

Precious Cells International (PCI) have opened a dedicated stem cell processing laboratory and cryopreservation facility at Brunel Science Park, London. PCI are offering dentists the opportunity to become affiliate healthcare professionals in order to offer their patients what could be a life-saving opportunity to preserve precious stem cells.

Dental pulp is considered a good source for mesenchymal stromal cells (MSCs) which are particularly useful for tissue engineering applications. Teeth are by far the most natural, noninvasive source of stem cells.

\section{LIVE SURGICAL TRAINING}

Experienced dental implant practitioners can move on to the next level with live surgical training from Dr Andrew Moore. The Advanced Implantology Course helps delegates to tackle difficult cases and more complex treatments with confidence. The programme takes place at the Advance Implant Clinic, Chelmsford in June and November 2012. Further details can be found on DENTSPLY Friadent's education website, www. courses4implants.com.

Dr Moore's course is designed for dentists who are already placing dental implants and wish to increase their clinical experience. The four live surgical sessions also feature immediate placement and immediate loading.

On completion, delegates should feel better prepared to manage bone

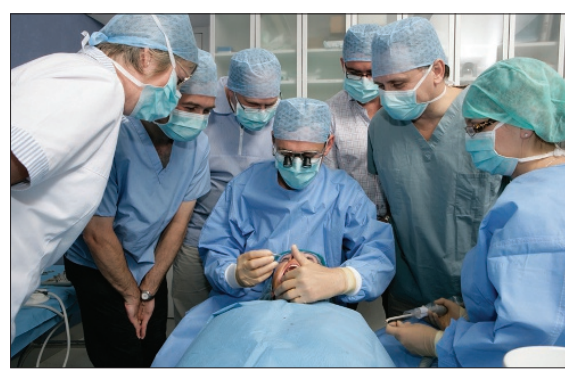

deficiencies and undertake immediate implant cases.

The course is approved by FGDP (UK) for accreditation of CPD hours and complies with GDC verifiable CPD requirements. Advance Implant Clinic is a purpose-built centre including state-of-the-art treatment facilities and a dedicated seminar room with surgery live on screen.

To book or for further information call 08000778650 or email courses. friadentuk@dentsply.com.

\title{
TAKE ADVANTAGE OF A WIRELESS INTERFACE
}

A central part of the Schick Digital Imaging System from Clark Dental is the CDR Elite. Schick WiFi expands upon the core CDR Elite package, adding portable functionality to the highly versatile digital X-ray system. With Schick WiFi users can take advantage of a wireless interface to transmit images from the sensor to the computer. This makes for complete unimpeded 360-degree chair access and simple room-to-room sensor transfer, speeding up workflow and providing the advantage of a single $\mathrm{X}$-ray system across multiple rooms.

To learn more about Schick WiFi call 01268733146 or visit www. clarkdental.co.uk.
Deciduous teeth, vital teeth removed for orthodontic purposes and wisdom teeth are all important sources of stem cells. A single vital tooth can provide sufficient stem cells but if the clinical necessity demands it two teeth (or four in a wisdom tooth clearance) are preferred.

In the case of deciduous teeth, Precious Cells recommend to their parent clients that loose teeth should not be allowed to fall out at home but that an appointment should be made to have the tooth, or teeth, properly extracted by a dentist. Precious Cells are building a list of dental practices where practitioners have registered to join the Precious Cells Healthcare Network.
For a dentist to legally extract a tooth for stem cell purposes they must be licensed by the Human Tissue Authority (HTA). The easiest way for a dentist to become licensed is to take out a third party licence from Precious Cells International.

The only liability for the dentist is an initial registration fee to cover the costs and administration for PCI to legally sub-license the dentist to join the programme.

The dentist will be paid a fee for each patient who has a tooth or teeth collected and successfully cryopreserved.

For more information and for prices and fees visit www.precious-cells.com or call 08454755221. 